
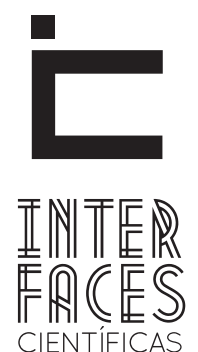

EDUCAÇÃO

ISSN IMPRESSO 2316-333X

E-ISSN 2316-3828

DOI-10.17564/2316-3828.2016v5n1p61-68

\title{
PRÁTICAS EDUCATIVAS PARA A TERCEIRA IDADE ATRAVÉS DE MEMÓRIAS E TRADIÇ̃̃ES CULTURAIS: CASO NUPATI/UFS
}

Helena Maria Fagundes dos Santos Braz ${ }^{1}$
Laura Cecília Fagundes dos Santos Braz

\section{RESUMO}

0 estudo é resultado de um trabalho realizado com os integrantes do Núcleo de Pesquisas e Ações da Terceira Idade - NUPATI/UFS, que abordou as práticas educativas vivenciadas pela Terceira Idade, em oficinas pedagógicas intituladas "Contos e Lendas", durante o período de 2012/2, com o intuito de resgatar as tradições, a memória e os costumes. Nas oficinas, foi observada melhoria na interação social entre os idosos e na capacidade da escuta, criatividade e interpretação, por meio do benéfico contato com os diversos tipos de gêneros literários, além de estimulá-los a contribuir, de maneira enriquecedora, com suas experiências, histórias cheias de vida, sentimentos e poesias, vivenciadas e acumuladas ao longo da existência de cada um.

\section{PALAVRAS-CHAVE}

Práticas Educacionais. Memórias. Terceira Idade. 


\section{ABSTRACT}

The study is the result of work done with the core members of Research and Actions for the Elderly - NUPATI / UFS, which addressed the educational practices experienced by the Third Age in educational workshops titled "Tales and Legends" during the 2012.2 period, in order to rescue the traditions, memory and customs. In the workshops it was observed improvement in social interaction between seniors and listening capacity, creativity and interpretation, through the beneficial contact with the various types of literary genres, and encourage them to contribute in enriching way, with their experience, stories full of life, feelings and poetry, experienced and accumulated throughout the life of each.

\section{KEYWORDS}

Educational Practices. Memories. Third Age.

\section{RESUMEN}

El estudio es el resultado del trabajo con el Núcleo de Pesquisas e Ações da Terceira Idade - NUPATI/ UFS, que abordó las prácticas educativas experimentadas por la Tercera Edad en talleres educativos titulados "Cuentos y leyendas", durante el período de 2012/2, con el fin de rescatar las tradiciones, la memoria y las costumbres. En los talleres, se observó una mejoría en la interacción social entre las personas mayores y en la capacidad de oír, creatividad y interpretación, a través del beneficioso contacto con los diferentes tipos de géneros literarios. Además, incentivarles a contribuir de manera exitosa, con sus experiencias, historias llenas de vida, sentimientos y poesía, y experiencias acumuladas durante la vida de cada uno.

\section{PALABRAS CLAVE}

Prácticas educativas. Recuerdos. Tercera edad. 


\section{INTRODUÇ̄̃̃O}

0 presente estudo é resultado de um trabalho realizado com os integrantes do Núcleo de Pesquisas e Ações da Terceira Idade (NUPATI) da Universidade Federal de Sergipe (UFS), que abordou as práticas educativas vivenciadas pela Terceira Idade, em oficinas pedagógicas intituladas Contos e Lendas, durante o período de 2012/2, com o intuito de resgatar as tradições, a memória e os costumes.

$\mathrm{Na}$ Antiguidade, a cultura de um povo era transmitida de pai para filho, de geração para geração, apenas por meio da oralidade, ficando a memória humana responsável por conservar as histórias, as crenças, os costumes dos indivíduos que participaram dessa esfera cultural e outros fatos relatados por seus antepassados. No entanto, com as transformações pela qual a sociedade brasileira passou devido ao processo de industrialização e aos avanços tecnológicos, a humanidade tem buscado novas conquistas e descobertas que trazem ao homem atual facilidades que os antigos não tinham (FREITAS; COSTA, 2012).

Parte-se do princípio que todo ser humano tem sua cultura e a promove na medida em que se comunica com o outro. A cultura das pessoas menos escolarizadas é rica em sabedoria popular, brotada do senso comum, da intuição, que é a origem do conhecimento erudito. Ao buscar compreender a identidade cultural de pessoas com mais de sessenta anos, deseja-se também refletir sobre a educação, bem como os mecanismos internalizados e as contribuições que trouxeram à sociedade. Sabe-se que uma grande parte dessa geração não possuía conhecimento escolarizado devido à política, ao sistema de exclusão, e a cultura da época não valorizava esse tipo de conhecimento, já que a leitura e a escrita eram privilégios de poucos (FREITAS; COSTA, 2012).

Vive-se em um sistema substancialmente injusto: além da exploração do trabalhador, da inflação, dos bolsões de pobreza e da perpetuação ou estratifica- ção das diferenças sociais, há uma visão penosa do idoso. Não é porque o sujeito chegou à velhice que não há mais nada a aprender. A sociedade precisa voltar os olhos para essa nova demanda. Os idosos devem estar preparados para uma participação ativa e transformadora da sociedade. É a educação ao longo da vida que deve fazer com que o sujeito conduza o seu destino e garanta uma cidadania ativa e não oprimida (CAPUZZO, 2012). Complementa a autora que a possibilidade de mudança após os 60 anos de idade é que faz o sujeito sair da estagnação em busca de alternativas, tornar-se crítico e atuante no e para o mundo, construindo novas histórias, ressignificando seus valores.

A pesquisa em questão, caracterizada como estudo de caso, foi realizada no NUPATI/UFS, sendo analisada qualitativamente. A abordagem deu-se juntamente com os alunos integrantes das oficinas, intituladas Contos e Lendas, e realizadas semestralmente, com duração de duas horas/aulas semanais, no período de 2012/2, cuja metodologia aplicada consistiu na aplicabilidade de atividades, tais como: leitura e interpretação de contos, lendas brasileiras e mundiais, mitos, fábulas, poesias, pensamentos, canções, os quais eram comentados, experimentados e reelaborados em redações.

Para tanto, a questão norteadora restringiu-se em saber: como as práticas educativas podem contribuir para o resgate de memórias e tradições culturais dos idosos integrantes do Nupati/UFS? A importância da realização desta pesquisa residiu-se na contribuição aos estudos sobre práticas educativas para idosos e sua contínua inserção na sociedade, e, o motivo que direcionou o presente tema a ser pesquisado esteve na inclinação pessoal, bem como na possibilidade de aprofundar-se nos estudos sobre políticas para a Terceira Idade.

As oficinas surgiram no intuito de incentivar os alunos do NUPATI a entrar em contato com os diversos tipos de gêneros literários, além de tornarem-se 
capazes de contribuir, de maneira enriquecedora, com suas experiências, histórias cheias de vida, sentimentos e poesias, vivenciadas e acumuladas ao longo da existência de cada um. Isso foi possível e gratificante. Criativos, críticos, inteligentes, os alunos transformaram as oficinas, trazendo uma memória viva e atual, um legado de suma importância para a sociedade.

\section{PRÁTICAS EDUCATIVAS PARA A TERCEIRA IDADE ATRAVÉS DE MEMÓRIAS E TRADIÇ̃̃ES CULTURAIS}

No passado, quando era costume sentar-se à beira da fogueira e ouvir relatos contados pelos guardiões da aldeia, tinha-se a certeza de que os ensinamentos seriam memorizados e transmitidos de geração a geração. E é aí que nasce a importância de contar histórias: em viver emoções hoje e reviver no futuro.

Pautado nisso, conceitua-se Memória como a "construção do passado, mas pautada em emoções e vivências, ela é flexível e os eventos são lembrados à luz da experiência subseqüente e das necessidades do presente" (FERREIRA, 2002, p. 321).

Um dos maiores estudiosos da memória, Halbwachs (2006 APUD NASCIMENTO; RAMOS, 2011, p. 454) impulsiona o seu caráter social, as referências exteriores, como a mola propulsora na acepção do tema. Para ele, não sendo inteiramente isolada e fechada, a memória individual provê o conhecimento da memória coletiva, tendo em vista que "para evocar o próprio passado, em geral, a pessoa precisa recorrer às lembranças de outras, e se transporta a pontos de referência que existem fora de si, determinados pela sociedade" (HALBWACHS, 2006, p. 72 APUD NASCIMENTO; RAMOS, 2011, p. 454).

Na evocação do depoimento da testemunha e do contexto referencial sobre o qual transitam o grupo e o indivíduo que o atesta, como forma de reconstruir o que se chama memória, Halbwachs (2006 APUD NASCIMENTO; RAMOS, 2011, p. 454) tratou de distinguir entre "memória histórica" e "memória coletiva", entendendo a primeira como reconstrutora dos elementos do presente da vida social e projetada sobre o passado reinventado, ao passo que a segunda cumpriria recompor magicamente o passado.

\begin{abstract}
Acredita-se, no liame deste pensamento que corrobora a memória coletiva, que o ato de recordar é algo que se realiza em sociedade, pela presença ou evocação, no chamamento a outros e a suas obras. É preciso ressaltar, entrementes, que mesmo sob as bases de uma comunidade, são os indivíduos que se lembram e essa memória individual representará um, entre muitos pontos de vista possíveis acerca da memória coletiva. Nossas lembranças mais pessoais não podem prescindir da ambiência coletiva onde estamos inseridos e, portanto, influenciados pelas suas transformações. Inferimos que a memória individual, não podendo se engendrar isoladamente, se coaduna às lembranças de outros, na interação diária com o grupo, em conversas e leituras que ajudam a interligar memória pessoal e memória social. (NASCIMENTO; RAMOS, 2011, p. 455).
\end{abstract}

Bosi (2004 APUD NASCIMENTO; RAMOS, 2011, p. 455) reitera a ideia de memória individual sintonizada com os grupos sociais: família, escola, Igreja, os quais ajudam a delinear as lembranças que figurarão como referências do sujeito. A autora, ao perscrutar um estudo da memória, levando em conta a inserção dos fatores sociais, opta por direcionar seu trabalho às lembranças das pessoas idosas, dado que elas já tiveram a experiência de percorrer toda uma sociedade, com todas as suas marcas e características que tais. Versando sobre as lembranças dos velhos, depreende-se que eles, na função de rememorar, não se encontram furtivos em sonhos que servem para apartá-los da vida cotidiana e seus ofícios, mas estão ocupados com o seu próprio passado de modo consciente, trazendo à tona o que dá contorno a sua vida.

Não é o que acontece com o sujeito adulto ativo, que se entretece com a vida presente e suas muitas exigências, sem tempo para se delongar em lembranças passadas, as quais, quando aparecem, figuram como sonhos, lazer, atividade contemplativa. 
Para Nascimento e Ramos (2011) a atividade de rememorar perpassa pela função social do sujeito que, no presente, reconstrói os fatos passados. Tal função será exercida quando este sujeito, antes ativo na sociedade de que faz parte, deixa de "contribuir" para o presente coletivo, alcançando o momento da velhice social que faz restar a ele apenas o encargo de lembrar, tornando-se a memória do grupo a que pertence. É a memória, nos dizeres de Pollak (1989 APUD NASCIMENTO; RAMOS, 2011, p. 455), que, ao definir o que é comum ao grupo e o que o diferencia, irá fundamentar e reforçar sentimentos de pertencimento.

Para Barros (2013), os costumes são modos de fazer e pensar que são compartilhados por muitas pessoas num determinado lugar, numa determinada época; fazem com que a realidade se transforme em algo familiar, previsível; e, por isso, alguns dos costumes se transformam em tradição. A tradição, por sua vez, é tudo aquilo que resiste ao tempo, que muda e permanece ao mesmo tempo e que foi feito pelos antepassados; não foi esquecido e foi apropriado.

Já Chauí (2000) explana que a memória é uma atualização do passado ou a presentificação do passado; é também registro do presente para que permaneça como lembrança.

Prado e Soligo (2005 APUD SORIANO, 2009, p. 56) por seu turno, ensinam que:

[...] ao recordar, passamos a refletir sobre como compreendemos nossa própria história e a dos nos cercam. Vamos nos inscrevendo numa história que não está mais distante e, sim, impregnada das memórias que nos tomam e da qual muitos outros fazem parte.

Entende-se prática educativa como sendo a forma de condução do ensino de um determinado tema. Os objetos utilizados para esse fim, quais os envolvidos e como se dará sua participação (até mesmo em que escala essa participação se dará) e quais os objetivos a serem alcançados são os elementos constitutivos da prática educativa. Na prática educativa, o professor tem um papel fundamental, ainda que ela não esteja centrada em suas ações, apenas dando pequenas orientações e fazendo observações. Mas deve-se lembrar que ele, o professor, teve uma participação, a maior parte das vezes solitária, durante todo o organizar da prática. Nesse processo, pode-se reconhecer na prática educativa a possibilidade da transgressão a partir das intenções do docente na mediação das interações entre o "mundo físico e o social” (BRAGANÇA ET AL., 2015, p. 2).

\begin{abstract}
A prática docente pode, em muitos casos, contemplar atividades diferenciadas que muitas vezes transcendem os limites de uma sala de aula. Ensinar e aprender envolve personagens que podem ser influenciados em sua dinâmica relacional por diversos fatores que permitem contribuir ou não para a criação de oportunidades de aprendizagem. Cabe ao educador definir metas e estratégias que poderão ser conjuntamente elaborados com os educandos visando à qualificação do ensino e do aprendizado. (BRAGANÇA ET AL., 2015, p. 2).
\end{abstract}

Estudo realizado por Assis e outros autores (2007), intitulado Ações Educativas em promoção da saúde no envelhecimento: a experiência do núcleo de atenção ao idoso da Unati/UERJ apresentou a experiência do Programa de Ações Educativas em Promoção de Saúde no Envelhecimento do Núcleo de Atenção ao Idoso, ambulatório da Universidade Aberta da Terceira Idade, da UERJ. Sendo interdisciplinar, o programa incluiu várias modalidades educativas, abertas aos idosos e usuários em geral. As atividades incluíram grupos de sala de espera, grupo fechado (Encontros com a Saúde), grupo aberto (Roda da Saúde) e produção de materiais educativos (folders e mural). 0 trabalho pautou-se numa visão de saúde articulada à qualidade de vida e concebe a educação como diálogo, troca de experiências, parceria, respeito ao outro, reflexão, problematização da realidade e busca de alternativas/escolhas possíveis.

As necessidades do idoso são consideradas no processo educativo, potencializando sua capacidade de aprender, criar, decidir, respeitando as particularidades do envelhecimento. A experiência valoriza e traz ao debate a complexidade e riqueza da dimensão 
educativa da saúde, consolidando-se como campo estratégico para a formação profissional e o desenvolvimento de modelo de atenção pautado no cuidado integral e no aprofundamento da articulação teórico- prática em promoção da saúde. No plano do ensino, o trabalho estimulou uma nova sensibilidade na cultura profissional, capaz de incluir o outro e seus saberes, considerando as condições socioeconômicas e culturais e sua relação com a saúde.

Na dinâmica do serviço, o programa representou um "abrir portas" à participação, aproximando profissionais e população, fortalecendo o compromisso com assistência de qualidade, centrada no vínculo, na responsabilização e na partilha dos desafios à qualidade de vida e saúde no envelhecimento.

Já Nunes e Silva (2011) abordaram sobre Serviço Social e a prática educativa com idosos da Universidade Aberta da Terceira Idade da UERJ que foi desenvolvido pela equipe de Serviço Social, em um programa de universidade de terceira idade, envolvendo jovens estudantes da universidade e contribuiu na socialização de informações e capacitação nas questões do envelhecimento e de políticas e direitos dos idosos, estimulando a participação social dos sujeitos envolvidos. Foram ressaltadas questões inerentes ao envelhecimento, a troca de experiências e o exercício da escuta em grupo entre os alunos e os coordenadores, bem como a possibilidade em constituir um olhar crítico dos idosos sobre a realidade social, ampliando sua percepção de sujeitos nesse processo.

Este aprendizado dos alunos idosos permitiu a percepção de que podem assumir postura de protagonismo na reivindicação de seus direitos sociais e também participar como sujeitos ativos de sua comunidade. 0 envolvimento de estudantes de Serviço Social no projeto propiciou capacitação nas questões do envelhecimento e das políticas para idosos como também trocas intergeracionais que promovem a reconstrução das representações sociais de idosos e jovens em nossa sociedade.
Em mais um estudo que elucidou práticas educativas, Miranda e Costa (2011), na pesquisa que tinha como título Práticas Educativas em espaço não formal com idosos: uma possível atuação pedagógica, analisaram a atuação do pedagogo no espaço não escolar do abrigo dos idosos. Neste texto, foi abordada a relação entre educação, prática educativa e Pedagogia, o espaço não formal e atuação do pedagogo neste espaço, tendo o seguinte questionamento: como o pedagogo poderia contribuir com os residentes do abrigo dos idosos, por meio de práticas educativas neste espaço não formal?

A metodologia privilegiou a abordagem qualitativa e, especificamente para atingir esse objetivo, optamos pela entrevista semiestruturada e pela observação participante, tendo como interlocutores idosos residentes do abrigo, equipe gestora do abrigo e pedagogos que atuaram neste espaço. Os resultados apontaram que a efetivação de trabalho do pedagogo no abrigo contribui de forma significativa para a valorização do idoso neste espaço.

Mendonça e outros autores, em 2013, desenvolveram estudo com tema $A$ experiência de oficinas educativas com idosos: (Re) pensando práticas à luz do pensamento Freireano que se tratou de um relato de experiência sobre a realização de oficinas educativas para idosos vinculadas a um projeto de extensão para promover o envelhecimento saudável e prevenir agravos à saúde no Programa Municipal da Terceira Idade. Foi abordada a temática do uso de medicamentos, desenvolvida pelos discentes e docentes do curso de Enfermagem da Universidade Federal de Viçosa-MG. As oficinas são estratégias terapêuticas que assumem uma importância basilar no contexto dos serviços de saúde, constituindo essencial instrumento de solidificação das relações de convívio e edificação do conhecimento acerca do processo saúde-doença.

O objetivo alcançado foi relatar experiência de trabalho junto aos idosos e subsidiar uma reflexão teórico-crítica sobre a prática das oficinas como estratégia 
de educação em saúde, à luz do pensamento Freireano. Constatou-se também que o espaço dialógico possibilitado pelas oficinas permitiu a interação entre 0 grupo, a expressão de vivências e desmitificação de ideias/conceitos quanto ao uso de medicamentos.

Ao citar os estados da arte e correlacionando-os com o objetivo do estudo, esclarece-se a mensagem principal que é a inserção de práticas educativas para as pessoas da Terceira Idade, sejam elas, na área da saúde, da cultura, da educação propriamente dita. 0 que se elucida é o resgate das tradições, da memória e dos costumes de cada idoso.

\section{CONSIDERAÇÕES FINAIS}

0 resgate de costumes, memórias e tradições de um povo em busca da identidade cultural em sociedade foi possível durante a realização deste estudo, dada a participação efetiva dos integrantes do NUPATI/UFS e a maneira de aplicabilidade do conhecimento adquirido por estes no cotidiano, podendo-se constatar e verificar que todo esse acervo e manifestação oriunda da experiência humana encontram-se vivos e disponíveis para serem conhecidos.

0 presente estudo resultou de um trabalho realizado com os integrantes do NUPATI/UFS, o qual abordou as práticas educativas vivenciadas pela Terceira Idade, em oficinas pedagógicas intituladas Contos e Lendas, durante o período de 2012/2, com o intuito de resgatar as tradições, a memória e os costumes.

Quão necessárias se fazem as práticas educativas para a terceira idade, seja em promoção da saúde no envelhecimento, seja nas atividades exercidas pela assistência social, como também, em ações que auxiliem a desvendar o interior de cada idoso, trazendo à tona os costumes, as memórias e tradições, os quais sempre serão contributos para o acervo da vida.
As práticas educativas para o público idoso proporcionam contribuição significativa por expressarem vivamente o compromisso social ao enfatizar a participação e oportunizar seu exercício, elas vislumbram um "abrir portas" ao pensamento criativo sobre a vida e ao desejo de atuar na construção de outras realidades possíveis, mais propícias à qualidade de vida no envelhecimento (ASSIS, 2007).

\section{REFERÊNCIAS}

ASSIS, Mônica de. et al. Ações educativas em promoção da saúde no envelhecimento: a experiência do núcleo de atenção ao idoso da UNATI/UERJ. 0 mundo da saúde São Paulo, v.31, n.3, jul-set. 2007. p.438-447. Disponível em: <http://www.saocamilo-sp.br/pdf/mundo_saude/55/15_promocao_da_saude.pdf>. Acesso em: 22 jun. 2015.

BARROS, José Márcio. Oficina: lembrar e esquecer: memória e diversidade cultural. Disponível em: <http://www.observatoriodadiversidade.org.br/ oficinadememoria/wp-content/uploads/2011/07/ Mem\%C3\%B3ria-e-Diversidade-OP-2011.pdf>. Acesso em: 13 jul. 2013.

BRAGANÇA, Bruno. Práticas educativas e ambientes de aprendizagem escolar: Relato de três experiências. Disponível em: <www.senept.cefetmg.br/galerias/Arquivos.../TerxaTema1Artigo17.pd>. Acesso em: 23 jun. 2015.

CAPUZZO, Denise de Barros. 0 trabalho educativo com idosos. Fragmentos de Cultura, Goiânia, v.22, n.1, jan-mar. 2012. p.37-47. Disponível em: <seer. ucg.br/index.php/fragmentos/article/download/2285/1397>. Acesso em: 22 jun. 2015.

CHAUÍ, Marilena. Convite à filosofia. São Paulo: Ática. Disponível em: <http://www.armazem.literario.nom.br/ autoresarmazemliterario/eles/martinhocarloshost/filosofia/27_modulo27.htm>. Acesso em 13 jul. 2013. 
FERREIRA, Marieta de Moraes. História, tempo presente e história oral. Rio de janeiro: Topoi, dez. 2002. p.314-332.

FREITAS, Silvane Aparecida de; Costa, Maria Jacira da. A identidade social do idoso: memória e cultura popular. UEMS-MS. 2012. Disponível em: <revistas2.uepg.br/index.php/conexao/article/viewFile/3718/2607>. Acesso em: 20 jun. 2015.

MENDONÇA, Érica Toledo. et al. A experiência de oficinas educativas com idosos: (re) pensando práticas à luz do pensamento Freireano. Rev. APS, v.16, n.4, dez. 2013. Disponível em: <http://bases.bireme.br/ cgi-bin/wxislind.exe/iah/online/?IsisScript=iah/iah.xi s\&src=google\&base $=$ LILACS\&lang $=$ p\&nextAction $=$ lnk GexprSearch=718805\&indexSearch=ID>. Acesso em: 23 jun. 2015.

MIRANDA, Joseval dos Reis; COSTA, Maria Lúcia Santos. Práticas educativas em espaço não formal com idosos: uma possível atuação pedagógica. V Colóquio
Internacional “Educação e Contemporaneidade”. São Cristóvão-SE, Brasil, 21 a 23 set. 2011.

NASCIMENTO, Lidiane Alves do; RAMOS, Marilúcia Mendes. A memória dos velhos e a valorização da tradição na literatura africana: algumas leituras. Crítica Cultural (Critic), Palhoça-SC, v.6, n.2, jul-dez. 2011. p.453-467.

NUNES, Alzira Teresa Garcia Lobato; SILVA, Laís Anastácia dos Santos. Serviço Social e a prática educativa com idosos da Universidade Aberta da Terceira Idade da UERJ. V Jornada Internacional de Políticas Públicas. Campus Universitário de Bacanga, São Luís-MA, 2011.

SORIANO, Mônica Elizabete Amaral. Contos de fadas e identidade infantil. 2009. 84f. Monografia (Licenciatura em Pedagogia) - Faculdade de Formação de Professores, Universidade do Estado do Rio de Janeiro, 2009. Disponível em: <http://www.ffp.uerj. br/arquivos/dedu/monografias/MEAS.2009.pdf>. Acesso em: 27 jul. 2013.

\begin{abstract}
1. Especialista em MBE Análise e Gestão de Negócios e Bacharel em Administração de empresas pela Universidade Federal de Sergipe - UFS; Docente da Universidade Paulista - UNIP, Unidade São José - Aracaju-SE; Membro do Grupo de Pesquisa em Educação, Cultura e Subjetividade (GPECS/UNIT/CNPq). E-mail: hbraz81@gmail.com

2. Graduada em Direito pela Universidade Tiradentes - UNIT (2007); Pós-graduada em Direito Público - UNIASSELVI; Acadêmica da Faculdade de Letras-Português da Universidade Federal de Sergipe - UFS; Ex-Membro da Comissão de Direitos Humanos da Ordem dos Advogados do Brasil, Seccional de Sergipe - OAB-SE; Ex-Conselheira Titular no Conselho Estadual dos Direitos da Criança e do Adolescente (representante da OAB/SE); Ex-Assessora Técnico-Jurídica da Fundação Hospitalar de Saúde-SE - FHS; Experiência em Advocacia, Assessoria e Assistência de Juiz; Ex-Subsecretária Substituta da $1^{\text {a }}$ Câmara Cível do Tribunal de Justiça do Estado de Sergipe - TJSE; Palestrante (temas jurídicos e referentes à Terceira Idade); Professora de Língua Portuguesa em projetos voluntários; Coordenadora e Facilitadora de oficinas e minicursos com temas voltados à Terceira Idade; Técnica Judiciária do Tribunal de Justiça do Estado de Sergipe - TJSE; Mestranda em Direitos Humanos pela Universidade Tiradentes - UNIT. E-mail: lauracbraz@hotmail.com
\end{abstract}

